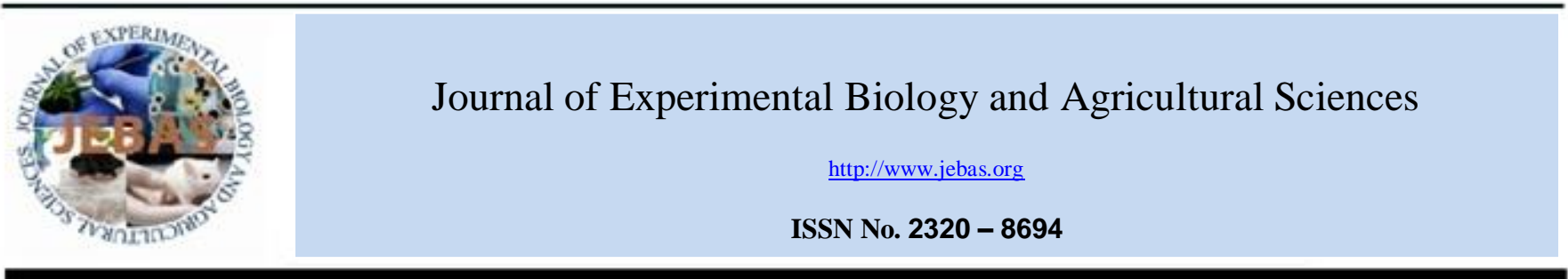

\title{
APPLICATION OF MATHEMATICAL MODEL TO THE ALMOST IDEAL DEMAND SYSTEM FOR THE FRUIT IMPORTS IN THE KINGDOM OF SAUDI ARABIA
}

\author{
Abdulaziz M.Al-Duwais ${ }^{1}$, Mahmoud M.Alderiny ${ }^{1}$, Alaa A.kotb ${ }^{1}$, Eman T. Alropy ${ }^{2}$, \\ Sharaf Eldin B. Ahamed ${ }^{1}$, Mirza B. Baig ${ }^{3}$ \\ ${ }^{1}$ Department of Agricultural Economics, College of Food and Agriculture Sciences, King Saud University, KSA \\ ${ }^{2}$ Department of Administrative Sciences, Community College, Princess Nourahbint, Abdulrahman University, KSA \\ ${ }^{3}$ Department of Agricultural Extension and Rural Society, College of Food and Agriculture Sciences, \\ King Saud University, KSA
}

Received - April 24, 2019; Revision - June 27, 2019; Accepted - July 20, 2019

Available Online - August 05, 2019

DOI: http://dx.doi.org/10.18006/2019.7(4).387.395

\section{KEYWORDS \\ Fruits \\ Imports \\ Almost ideal demand system \\ Elasticities \\ Kingdom of Saudi Arabia}

\begin{abstract}
The main objective of this research was to estimate the demand function for imports of apples, oranges, and bananas to Saudi Arabia, as these are the most important fruits in the Saudi diet. Using annual data for imports of oranges, apples, and bananas to the Kingdom during the period 1980-2015, an almost ideal demand system model was utilized to identify the competitive relationships between the main fruits(apples, oranges, and bananas). The coefficients of the model were estimated using the seemingly unrelated regression and iterative-seemingly unrelated regression methods, with addition, homogeneity, and symmetry conditions imposed so that the estimated models conform to demand theory and satisfy the Slutsky condition. The elasticities of price, cross-sectional, and expenditure demand for each commodity were estimated. The results found that the almost ideal demand system for apples, oranges, and bananas fulfills the addition requirement. In addition, the demand equations for the Kingdom's imports of these fruits are homogenous at zero-grade, and it was found that all the price elasticities (self and cross) and the elasticity of expenditure are consistent with economic theory.
\end{abstract}

* Corresponding author

E-mail: Salaagib@ksu.edu.sa(Sharaf Eldin B.Ahamed)

Peer review under responsibility of Journal of Experimental Biology and Agricultural Sciences.

Production and Hosting by Horizon Publisher India [HPI] (http://www.horizonpublisherindia.in/).

All rights reserved.
All the articles published by Journal of Experimental Biology and Agricultural Sciences are licensed under a Creative Commons Attribution-NonCommercial 4.0 International License Based on a work at www.jebas.org.

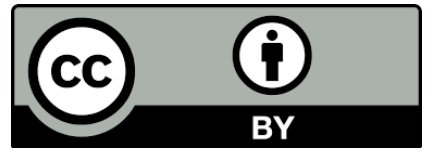




\section{Introduction}

Saudi Arabia imports most of its fruits (apples, bananas, and oranges). Imports of these goods have increased steadily over the past three decades due to an increase in the population, consumer preferences for healthy goods, and the increase in the number of pilgrims each year. Saudi Arabia is a booming market in the Middle East, where the population growth rate has witnessed a steady annual increase. The market is characterized by high purchasing power and diversified sources of imports. The Kingdom imports apples, oranges, and bananas (which are the major daily consumed fruits) from several countries including Egypt, South Africa, the USA, Chile, the Philippines, Turkey, Lebanon, France, India, and Pakistan. Some statistical sources have reported that the fruit market for apples, oranges, and bananas has grown by $3 \%$ per year and that there are seasons in which there is a particular increase in the demand, such as during the holy month of Ramadan and the pilgrimage. It is well known that importing apples, oranges, and bananas incurs financial costs related to refrigerated storage during sea transport between countries and land transport within Saudi Arabian markets as well as higher freight and insurance costs due to global inflation and exchange rates. These costs contribute to the overall rise in and volatility of prices at the global and national levels for this commodities. Appendix 1 shows the quantities, prices, and import value of apples, oranges, and bananas during the period of 1980 to 2015. The annual imports of apples ranged from a minimum of 42,134 tons in 1986 to a maximum of 205,546 tons in 2015(Central bureau of statistics, 2016). The average amount of apples imported during the period was 128,599 tons; the amount of apple imports is growing at an annual rate of $1.7 \%$.

The annual quantity of orange imports ranged from a minimum of 65,691 tons in 1987 to a maximum of 386,611 tons in 2015.The average quantity of oranges imported during the study period was 244,138 tons; the annual growth rate is $2.9 \%$. Finally, the table shows that the annual quantity of banana imports ranged between a minimum of 55,581 tons in 1987 to a maximum of 307,420 tons in 2010. The average quantity of bananas imported during the period studied was 174,574 tons; banana imports are growing at an annual rate of $2.4 \%$ (Central bure9au of statistics, 2016).

In terms of the value of imports, the average value of imported apples during the period 1980 - 2015 amounted to 77,605 thousand Saudi Riyals (SR). In addition, the average value of orange imports during this period amounted to SR97,849 thousand and the average value of banana imports during the same period amounted to SR 75,211 thousand (Central bureau of statistics,2016).

In terms of import price per ton, the average import price for apples, oranges, and bananas was 567, 380, and 404 US dollars per ton, respectively. The annual rate of growth in prices was $1.9 \%, 1.1 \%, 1.6 \%$ for apples, oranges, and bananas, respectively, during the period 1980-2015(Central bureau of statistics, 2016). Based on this previous information, the importance of studying the demand systems involved in the import of fruit (apples, oranges, and bananas) to Saudi Arabia is clear. This study is needed to provide the information necessary for the development of appropriate economic policies related to international trade with fruit-exporting countries.

In the application of the almost ideal demand system (AIDS), Alston \& Chalfant (1993) and Buse (1994) reported that the AIDS model is most commonly used to analyze demand-order systems due to its flexibility, as well as its other vector images and suitability for aggregation among consumers. AIDS is easy to interpret when estimating aggregate or non-aggregated data, it conforms to a specific preference structure, and is consistent with the economic analysis of well-being because it is derived from a specific cost function. It also facilitates the imposition of additively, homogeneity, and symmetry constraints. This model is characterized by the fact that the results and estimates it provides allow for the derivation of cross and complementary elasticities of demand (Deaton \& Muellbauer 1980). Further, Al-Khariji $\&$ Vetterstone (1997) used the bootstrap method to estimate the parameters of the model of two application systems: the AIDS system, and the Armington system. The application equation resulting from the integration of these two systems was applied to analyze and estimate the price and income elasticities of demand for chicken in Saudi Arabia.

Similarly, Al-Ruwis (2004) identified the almost ideal demand system (AIDS) for rice imports from the main import sources to Saudi Arabia during the period of 1992-1998 based on monthly data for rice imports to identify the extent of the separatism of the import sources and the competitive relations among them. Expenditure on rice imports and the coefficients of the model were estimated simultaneously using the iterative-SUR method under the restrictions of symmetry and addition. The model coefficients were also used to calculate the elasticity of the demand and the self and cross price to determine the nature of the relationships, the competitiveness of sources of rice import to the Kingdom, and the nature of the demand.

Further, Al-Qahtani (1998) used the Rotterdam system and the linear approximation of the system closest to the ideal for foreign rice trade in Saudi Arabia in order to study the geographical demand systems for rice imports. This had been carried out to provide the basic information necessary for the development of consumer and import policies, namely, the assessment of price elasticities and expenditures. The study by Al-Zum (2001) estimates the demand function of citrus imports to Saudi Arabia using the semi-optimal demand model to identify the relationship 
between citrus commodities (oranges, tangerines, and lemons) and the competitive relations between orange import sources. The coefficients of the model were estimated using the unregulated regression method, or seemingly unrelated regression (SUR), and the imposition of restrictions (addition, homogeneity, and symmetry), so that the estimated models conform to the demand theory and achieve the Slutsky condition. This determined the elasticities of price cross and expenditure for each main source of citrus fruit.

Al-Ruwis \& Al-Dirini (2008) estimated the demand function for Saudi imports of live sheep for meat using the almost ideal demand system. It was found that the almost ideal demand system for imported live sheep fulfills the addition requirement. It was determined that, in the demand equations for imports (Turkey, Syria, and Sudan), all the price elasticities (self and cross) and the elasticity of expenditure are consistent with economic theory, but differ in degree. Similarly, Meshaal (2018) estimated the demand for meat in Egypt by using the almost ideal demand system. The results showed that the percentage of consumption expenditure in Egypt for red meat is higher than the consumption expenditure for both poultry and fish. The signal and value of cross-elasticity of demand indicate that red meat, poultry, and fish are considered to be commodities, and elasticity suggests that these three groups (red meat, poultry, and fish) are essential commodities.

Demand for fruit in the Kingdom depends on the import of the most important fruit commodities (apples, oranges, and bananas) from the global market. This is because of the low domestic production due to climatic and environmental conditions that are not suitable for the production of these fruits. The increase in population; rise in purchasing power; trend in consumer preferences for these commodities; and rapid growth of restaurants, hotels, and wedding palaces are important factors in the increase in the quantities imported annually. A recent survey of consumer demand in the Kingdom for apple, orange, and banana-related products showed the demand structure for these imports. It also identifies the most important factors affecting it, intrinsic price elasticities, cross elasticities, and income elasticities,all of which contribute additional important information that is necessary for economic planning in the field of foreign trade.

The primary aim of this study is to develop a statistical estimation of the demand model for the Kingdom's, apples, oranges, and bananas imports. The AIDS model was used to represent the system of expenditure share equations for imports of these fruits. The study also aims to achieve a number of specific objectives, which are (i) Estimating the parameters of the proposed model using the non-linear least squares method, and then estimating the possibility of testing the significance of regression coefficients (ii) Conducting statistical tests to verify the restrictions placed on the system of import demands of fruits for the Kingdom, namely, addition, homogeneity, symmetry and (iii) Calculating the self, cross, and income elasticities, and then indicating the extent of the effect of the relative changes in both prices and total expenditure on the relative changes in the quantities required for all three imported fruit types.

To achieve the above research objectives, the study relied on time series data from 1980 to 2015 obtained from the FAO publication. This series included data on the amount of imports, $q_{i t}$, of the fruits studied, apples, bananas, and oranges, as well as the values of spending, $m_{i t}$, on these quantities. The price data series has been calculated as $p_{i t}=m_{i t} / q_{i t}$; Appendix 1 represents data showing the general trend in expenditure shares during the period under study.

\section{Materials and Methods}

\subsection{Almost ideal demand system (AIDS) model}

The AIDS application model, which was developed by Deaton \& Muellbauer (1980), is very popular in applied aspects of the study and analysis of import demand. This model is derived from an expenditure function that reflects the importer's behavior in the trade-off between a numbers of commodities (Yang \&Koo, 1994).

Assuming that $n$ is the number of imported goods, $\left(p_{1 t}, p_{2 t}, \ldots, p_{n t}\right)$ is the price of these goods during the period of time, and $\left(q_{1 t}, q_{2 t}, \ldots, q_{n t}\right)$ are the quantities imported during the period of time $t$, expenditure $m_{t}$ on imports of goods during the period of time $t$ can be expressed by the equation $m_{t}=\sum_{i=1}^{n} p_{i t} q_{i t}$.

If $w_{i t}$ expresses the share of commodity $i$ from the total expenditure on imports for the goods under study during the period of time ${ }^{t}$, the systems of equations for the import of commodities examined by AIDS can take the following form:

$$
\begin{array}{r}
w_{i t}=\alpha_{i}+\sum_{j=1}^{n} \beta_{i j} \log _{e}\left(p_{j t}\right)+\gamma_{i} \log _{e}\left(m_{t} / P_{t}\right)+\varepsilon_{i t}, \\
i=1,2, \ldots, n, \quad t=1,2, \ldots, T
\end{array}
$$

Where:

$T:$ the number of views, $n$, is the number of imported goods.

$\varepsilon_{i t}$ : is the random error of the equation of the share of the item, $i$, of the expenditure on imports during the period of time, $t$. It is assumed that the vector random errors in the period of time $t$, $\varepsilon_{t}=\left(\varepsilon_{1 t}, \varepsilon_{2 t}, \ldots, \varepsilon_{n t}\right)^{\prime}$ follows a multiple natural distribution; its expected value is zero. It has a matrix of variation and heterogeneity $\Sigma$, and it is fixed from one view to another, that is, $\varepsilon_{t} \sim N_{n}(0, \Sigma)$ 
$P_{t}:$ is the general price index in the time period $t$.It is determined by the following formula:

$$
\ln P_{t}=\alpha_{0}+\sum_{k=1}^{n} \alpha_{k} \log _{e}\left(p_{k t}\right)+\frac{1}{2} \sum_{i=1}^{n} \sum_{j=1}^{n} \beta_{i j} \log _{e}\left(p_{i t}\right) \log _{e}\left(p_{j t}\right)
$$

\subsection{Limitations of the AIDS model}

There are a number of constraints related to the order system that make the model consistent with the theory of demand, which are:

\subsubsection{Add up constraint}

This constraint is the result of the assumption of linearity of the budget and preferences of the consumers. These results are in the total value of the Marshall and Hixan demands being equal to the total expenditure. To achieve the additional constraint, $m_{t}=\sum_{i=1}^{n} p_{i t} q_{i t}$, the following assumptions should be made about the parameters of the model:

$\sum_{i=1}^{n} \alpha_{i}=1, \quad \sum_{i=1}^{n} \gamma_{i}=0, \quad \sum_{i=1}^{n} \beta_{i j}=0$

\subsubsection{Homogeneity}

The AIDS demand model is based on the assumption that it is homogeneous from class zero, meaning that the increase in prices and income available to spend on the goods studied in the same proportion does not result in a relative increase in the required quantities of these commodities. To achieve this limitation, the following condition should be met:

$\sum_{j=1}^{n} \beta_{i j}=0$

\subsubsection{Symmetry}

This limitation shows how cross-elasticities are associated. To achieve this limitation, the following assumptions must be made:

$\beta_{i j}=\beta_{j i}, \quad i \neq j=1,2, \ldots, n$

\subsubsection{Negativity}

This limitation means that the Slutsky compensatory matrix, which includes all the intrinsic and cross-elasticities, must be semi-specific and negative. This matrix is the same as the class and takes the following form:

$$
\left[\begin{array}{ccccc}
e_{11} & e_{12} & \ldots & e_{1 n} & \\
e_{21} & e_{22} & \ldots & e_{2 n} & \\
\ldots & \ldots & \ldots & \ldots \\
e_{n 1} & e_{n 2} & \ldots & e_{n n} &
\end{array}\right]
$$

Since $e_{i i}$ represents the self-price elasticity, $i \neq j$ ‘ $e_{i j}=e_{j i}$ expresses the elasticity of cross-price, and this restriction is achieved only if there are some elements of the main diameter $\left(e_{i i} \leq 0\right)$

\subsection{Calculation of elasticities from the parameters of the demandmodel (AIDS)}

The self- and cross-price elasticities can be calculated from the demand model (AIDS) by applying the following Marshall equation (Gravelle \& Rees, 1992; Nicholson, 1992; Greene, 2003).

$e_{i j}=\frac{\beta_{i j}-\gamma_{i}\left(w_{j}-\gamma_{j} \ln (m / P)\right)}{w_{i}}-\delta_{i j}, \quad \delta_{i j}=\left\{\begin{array}{l}1 \text { if } i=j \\ 0 \text { if } i \neq j\end{array}\right.$

If $i=j$, it is possible to obtain the own-price elasticity, which expresses the responsiveness of the required quantity of a given commodity to the change in its price. If $i \neq j$, it is possible to obtain the cross-price elasticity, which expresses the extent to which the required amount of the commodity $i$ responds to the change in the price of the commodity $j$.

\subsection{Income elasticity of demand}

Income elasticity of demand expresses the extent to which the required quantity of a particular commodity responds to the change in a consumer's income, and it is measured by the percentage change in the quantity of the commodity to the relative change in income. It is computed as:

$\eta_{i}=1+\frac{\gamma_{i}}{w_{i}}, \quad i=1,2, \ldots, n$

\subsection{Statistical estimation of the demand model}

In the case of compensation by index formula, $\log _{e}\left(P_{t}\right)$, on the right side of equation (2), the formula for the share of commodity $i$ of the expenditure on imports in the period of time $t$ becomes non-linear in the coefficients, and can be expressed as follows:

$$
\begin{aligned}
w_{i t}= & \alpha_{i}+\sum_{j=1}^{n} \beta_{i j} \log _{e}\left(p_{j t}\right)+\gamma_{i}\left\{\log _{e}\left(m_{t}\right)-\alpha_{0}-\right. \\
& \left.\sum_{j=1}^{n} \alpha_{j} \log _{e}\left(p_{j t}\right)-\frac{1}{2} \sum_{i=1}^{n} \sum_{j=1}^{n} \beta_{i j} \log _{e}\left(p_{i t}\right) \log _{e}\left(p_{j t}\right)\right\}
\end{aligned}
$$

Since the share of imported good $n$, out of the total expenditure $w_{n t}$ on the imported goods under study, can be deducted from other shares $\left[w_{n t}=1-\sum_{i=1}^{n-1} w_{i t}\right]$, the number of exchange-rate equations in the system of equations of demand for imported goods is equivalent and is expressed as follows:

Journal of Experimental Biology and Agricultural Sciences http://www.jebas.org 


$$
\left[\begin{array}{l}
w_{1 t} \\
w_{2 t} \\
\cdots \ldots \\
w_{(n-1) t}
\end{array}\right]=
$$$$
\left[\begin{array}{c}
\alpha_{1}+\sum_{j=1}^{n} \beta_{1 j} \log _{e}\left(p_{j t}\right)+\gamma_{1}\left\{\log _{e}\left(m_{t}\right)-\log _{e} P_{t}\right\}+\varepsilon_{1 t} \\
\alpha_{2}+\sum_{j=1}^{n} \beta_{2 j} \log _{e}\left(p_{j t}\right)+\gamma_{2}\left\{\log _{e}\left(m_{t}\right)-\log _{e} P_{t}\right\}+\varepsilon_{2 t} \\
\ldots \ldots \ldots \ldots \ldots \ldots \ldots \ldots \ldots \ldots \ldots \ldots \ldots \ldots \ldots \ldots \ldots \ldots \ldots \ldots \ldots \ldots \ldots \ldots \ldots \ldots \\
\alpha_{n-1}+\sum_{j=1}^{n} \beta_{n-1, j} \log _{e}\left(p_{j t}\right)+\gamma_{n-1}\left\{\log _{e} m_{t}-\log _{e} P_{t}\right\}+\varepsilon_{n-1, t}
\end{array}\right],
$$

The above example contains an anonymous $\{(n(n+2)\}$ parameter:

$$
\mathrm{B}=\left(\alpha_{0}, \alpha_{1}, \ldots, \alpha_{n}, \beta_{11}, \beta_{12}, \ldots, \beta_{n n}, \gamma_{1}, \ldots, \gamma_{n-1}\right)^{\prime}
$$

It can then be estimated using the nonlinear least squares (NLS) method. A characteristic of this estimate is that it is consistent, and its distribution is closer to normal distribution when the sample size is sufficiently large (Hahn, 1994; Greene, 2003). In order to obtain this estimate, tests can be made to verify the significance of regression coefficients, form limitations, self and cross-elasticities, and elasticity of income or expenditure (SAS, 2001; SAS, 2018).

\subsection{Characterization of the Saudi application model for all three imported fruit types}

The study includes the almost ideal demand for three types of fruit (apples, oranges, and bananas). The equation for the share of total imported fruit can be expressed in the following manner:

$$
\begin{aligned}
w_{i t}= & \alpha_{i}+\sum_{j=1}^{3} \beta_{i j} \log _{e}\left(p_{i j}\right)+\gamma_{i}\left\{\log _{e}\left(m_{t}\right)-\alpha_{0}-\right. \\
& \left.\sum_{j=1}^{3} \alpha_{j} \log _{e}\left(p_{j t}\right)-\frac{1}{2} \sum_{i=1}^{3} \sum_{j=1}^{3} \beta_{i j} \log _{e}\left(p_{i t}\right) \log _{e}\left(p_{j t}\right)\right\}
\end{aligned}
$$

Where:

$m_{t}$ : Expresses the total expenditure in dollars on imported fruits of all three types, $m_{t}=p_{1 t} q_{1 t}+p_{2 t} q_{2 t}+p_{3 t} q_{3 t}$

$\left(q_{3 t}, q_{2 t}, q_{1 t}\right)$ :Expresses the quantities imported, in tons of fruit, of all three types (apples, oranges, and bananas, respectively) during the period of time $t, t=1,2, \ldots, 36$.

$\left(p_{3 t}, p_{2 t}, p_{1 t}\right)$ :Expresses import prices, in dollars per ton, of apples, oranges, and bananas, respectively, during the time period $t$.

Since there are three equations, the systems of equations to be evaluated include the following two equations:

$$
\begin{aligned}
& \text { Apple eq. } \begin{aligned}
w_{1 t}= & \alpha_{1}+\sum_{j=1}^{3} \beta_{1 j} \log _{e}\left(p_{j t}\right)+\gamma_{1}\left\{\log _{e}\left(m_{t}\right)-\alpha_{0}-\sum_{j=1}^{3} \alpha_{j} \log _{e}\left(p_{j t}\right)\right. \\
& \left.\left.-\frac{1}{2} \sum_{i=1}^{3} \sum_{j=1}^{3} \beta_{i j} \log _{e}\left(p_{i t}\right) \log _{e}\left(p_{j t}\right)\right\} \log _{e} P_{t}\right\}+\varepsilon_{1 t} \\
\text { Orange eq. } w_{2 t}= & \alpha_{2}+\sum_{j=1}^{3} \beta_{2 j} \log _{e}\left(p_{j t}\right)+\gamma_{2}\left\{\log _{e}\left(m_{t}\right)-\alpha_{0}-\sum_{j=1}^{3} \alpha_{j} \log _{e}\left(p_{j t}\right)\right. \\
& \left.\left.-\frac{1}{2} \sum_{i=1}^{3} \sum_{j=1}^{3} \beta_{i j} \log _{e}\left(p_{i t}\right) \log _{e}\left(p_{j t}\right)\right\} \log _{e} P_{t}\right\}+\varepsilon_{2 t}, \\
t= & 1,2, \ldots, 36
\end{aligned}
\end{aligned}
$$

\subsection{Limitations of the Saudi demand model for imported fruit}

The constraints of addition, homogeneity, and symmetry are expressed in the following equations:

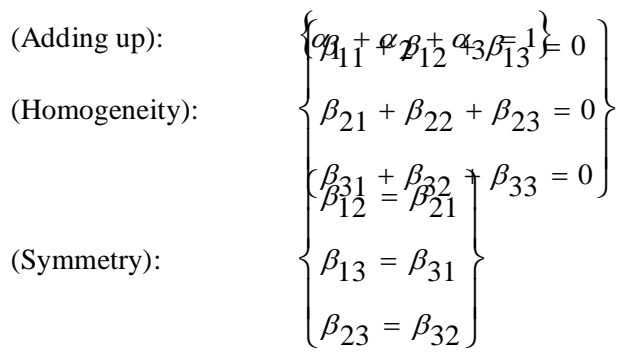

Negativity is achieved only if the compensatory Slutsky matrix, which includes all the own- and cross-elasticities,

$$
\left[\begin{array}{lll}
e_{11} & e_{12} & e_{13} \\
e_{21} & e_{22} & e_{23} \\
e_{31} & e_{32} & e_{33}
\end{array}\right]
$$

indicates semi-specific negativity, or some of the main diameter elements must be $\left(e_{i i} \leq 0\right)$

\section{Results and Discussion}

\subsection{Market shares of imported fruits}

The table 1 and figure 1 shows the market shares of imported fruits during the study period (1980 - 2015).

Table 1 Market shares of KSA imported fruits (1980-2015)

\begin{tabular}{|ccc|}
\hline Fruit type & Average value (thousand dollars) & (\%) Market share \\
\hline Apples & 77,605 & 31 \\
\hline Oranges & 97,849 & 39 \\
\hline Bananas & 75,211 & 30 \\
\hline Total & 250,665 & 100 \\
\hline \multicolumn{2}{c}{ Source: Computed from the data of appendix No. (1) }
\end{tabular}




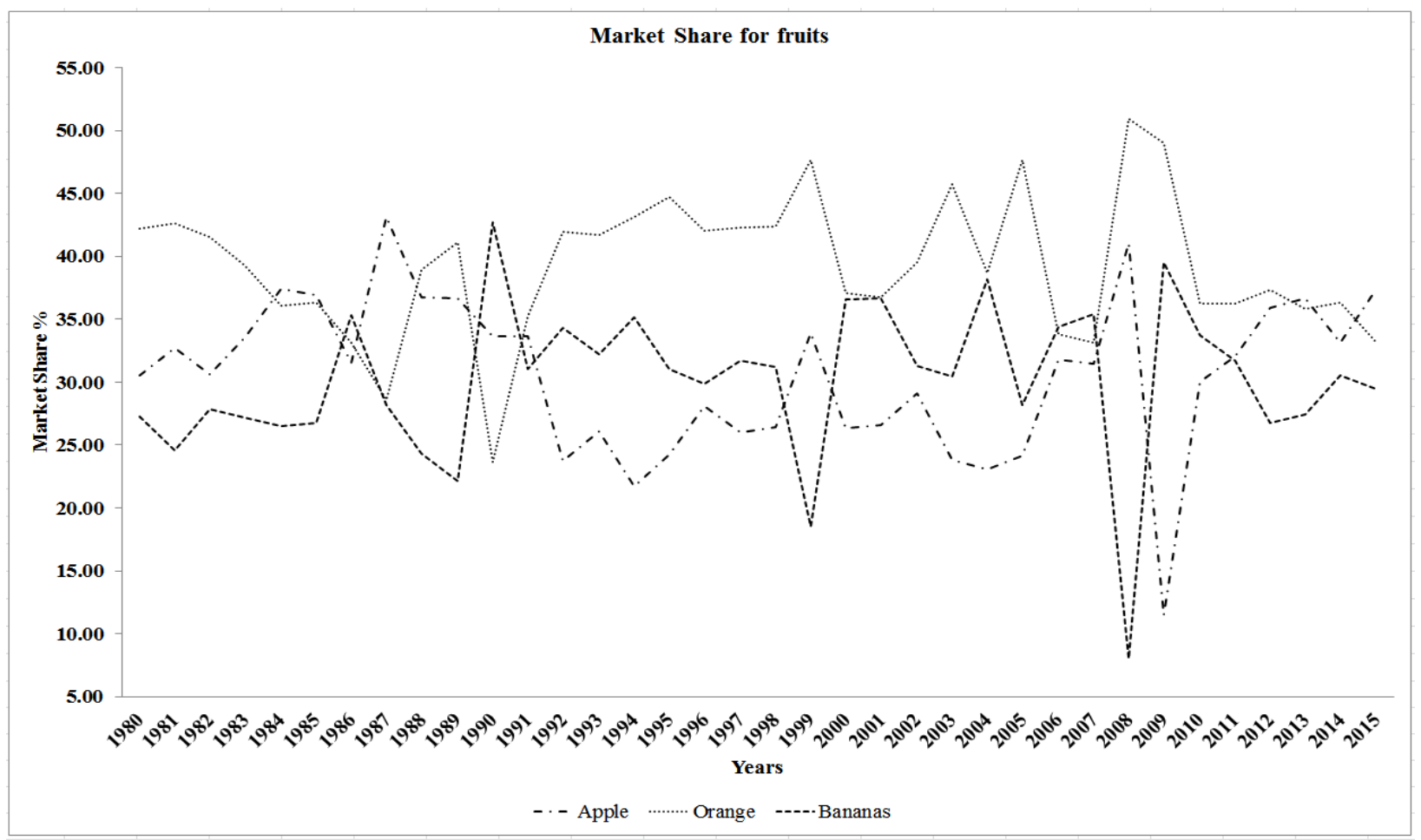

Figure 1 Graphic presentation of market shares

\subsection{Estimated Parameters:}

The results of the estimates of the non-linear least squares (NLS) for the properties of the equation systems shown in equation 13 and table 2. The Saudi demand system (AIDS) for the imported fruits in this study consists of three equations that represent the expenditure share $\left(w_{1 t}\right)\{n(n+2)-1=14\}$.

From the calculated statistical $t$ value and significance values $\operatorname{Pr}>\mid t$ value $\mid$, it was observed that (i) The regression constant of the first equation, $\alpha_{1}$, is significant at the 0.05 significance level, while the regression constant of the second equation, $\alpha_{2}$, and the third, $\alpha_{3}$, are insignificant at the 0.05 significance level (ii) for price logarithms $\log _{e}\left(p_{i}\right)$, all parameters, $\beta_{i j}$, are significant at a 0.05 significance level and (iii) for expenditure coefficients $\log _{e}(m / P)$ parameters, it is noted that each $\gamma_{1}$ ' $\gamma_{2}$ is significant at a 0.05 significance level.

\subsection{Demand Restrictions}

Table 3 shows the constraints of the demand function, its estimates, and the results of the significance test.

From the statistical values of the test of $t$ value and probability viewer $P_{\text {_ }}$ value, it was reported that the Saudi demand equations for the three types of imported fruit (equation 13) satisfies the addition, homogeneity constrain. The detail of noted constraints is as follows

\subsubsection{Addition constraint}

Since the probability $\{\operatorname{Pr}(t>1.35)=0.182\}$ is greater than a 0.05 significance level, the null hypothesis can be accepted, $H_{10}: \alpha_{1}+\alpha_{2}+\alpha_{3}=1$. It is clear from the model that the system of Saudi demand equations for the three types of imported fruit (13) satisfies the addition and symmetry constrain.

\subsubsection{Homogeneity constraint}

Since the possibilities observed, $\{\operatorname{Pr}(t>0.4)=0.697\}$, $\{\operatorname{Pr}(t>|-0.95|)=0.352\}$ and ,are each greater thana 0.05 significant level, the three null hypotheses can be accepted, $H_{20}: \beta_{11}+\beta_{12}+\beta_{13}=0, H_{30}: \beta_{21}+\beta_{22}+\beta_{23}=0$, and $H_{40}: \beta_{31}+\beta_{32}+\beta_{33}=0$. As a result, the model of the system of equations for Saudi demand for all three types of imported fruit achieves the requirement of homogeneity.

\subsubsection{Symmetry constraint}

Since the probabilities observedare $\{\operatorname{Pr}(t>0.67)=0.509\}$, $\{\operatorname{Pr}(t>1.28)=0.207\}$ and, $\{\operatorname{Pr}(t>|-0.77|)=0.449\}$ each of which is greater than the 0.05 significance level, the three null hypothesis 
can be accepted, $H_{50}: \beta_{12}=\beta_{21} H_{60}: \beta_{13}=\beta_{31}$, and $H_{70}: \beta_{23}=\beta_{32}$. In addition, it is clear from the model that the system of equations for Saudi demand of all three types of imported fruit achieves the symmetry constraint.

\subsection{Estimated Elasticities}

From the results of the estimates of regression coefficients of model (13) shown in Table (2), the own- and cross-price elasticities were calculated by applying equation (7), and the expenditure elasticities were calculated by applying equation (8), at the average rates of expenditure share, $\bar{w}_{1}=0.306$, $\bar{w}_{2}=0.392, \quad$ and $\bar{w}_{3}=0.302$, and the average amount, $\overline{\log _{e}(m / \hat{P})}=12.898$. The results are summarized in Table 4 .

\subsubsection{Saudi demand for imported apples}

From the table 4, it was observed that (i) The own-price elasticity, $e_{11}$, is significant at a significance level of 0.01 . In addition, its estimation is $\hat{e}_{11}=-0.276$, indicating that the Saudi demand for apples is less elastic for the price of apple imports, and that an increase in apple import prices of $10 \%$ would lead to a $2.76 \%$ decrease in the amount of imported apples (ii) The cross-price elasticity, $e_{12}$,is significant at a significance level of 0.01 , indicating $\hat{e}_{12}=-0.303$. Therefore, the Saudi demand for apples is less elastic for the price of orange imports, and that a $10 \%$ increase in the price of imported oranges would lead to a $3.03 \%$ decrease in the amount of imported apples (iii) The cross-price elasticity, $e_{13}$, is significant at a significance level of 0.05. Additionally, its estimate, $\hat{e}_{13}=-0.236$, indicates that the Saudi demand for apples is less elastic for banana import prices. Therefore, a $10 \%$ increase in the import price of bananas would lead to a $2.36 \%$ lower quantity of imported apples and (iv) the demand elasticity of the expenditure demand, $\eta_{1}$, is significant at a significance level of 0.01. In addition, its estimate, $\hat{\eta}_{1}=0.815$, indicates that the Saudi demand for imported apples is less elastic for the allocated portion of the total expenditure on all three types of imported fruit. A $10 \%$ increase in this expenditure would increase the required quantity of imported apples by $8.15 \%$.

Table 2 Results of NLS estimates for the parameters of equation (13)

\begin{tabular}{|ccccc|}
\hline Parameter & Estimate & $\begin{array}{c}\text { Approx } \\
\text { Std Err }\end{array}$ & t Value & $\begin{array}{c}\text { Approx } \\
\text { Pr }>|\mathrm{t}|\end{array}$ \\
\hline$\alpha_{1}$ & 0.981 & 0.321 & 3.05 & 0.005 \\
\hline$\alpha_{2}$ & -0.273 & 0.252 & -1.08 & 0.287 \\
\hline$\alpha_{3}$ & 0.293 & 0.310 & 0.95 & 0.351 \\
\hline$\beta_{11}$ & 0.163 & 0.051 & 3.21 & 0.003 \\
\hline$\beta_{12}$ & -0.075 & 0.037 & -2.06 & 0.048 \\
\hline$\beta_{13}$ & -0.088 & 0.036 & -2.43 & 0.021 \\
\hline$\beta_{21}$ & -0.075 & 0.037 & -2.06 & 0.048 \\
\hline$\beta_{22}$ & 0.210 & 0.042 & 4.96 & $<.0001$ \\
\hline$\beta_{23}$ & -0.134 & 0.032 & -4.16 & 0.000 \\
\hline$\beta_{31}$ & -0.088 & 0.036 & -2.43 & 0.021 \\
\hline$\beta_{32}$ & -0.134 & 0.032 & -4.16 & 0.000 \\
\hline$\beta_{33}$ & 0.222 & 0.040 & 5.63 & $<.0001$ \\
\hline$\gamma_{1}$ & -0.056 & 0.025 & -2.30 & 0.028 \\
\hline$\gamma_{2}$ & 0.054 & 0.019 & 2.80 & 0.009 \\
\hline$\gamma_{3} 0-\gamma_{1}-\gamma_{2}$ & 0.002 & 0.024 & 0.10 & 0.925 \\
\hline
\end{tabular}

Source: Computed from the data of appendix No. (1)

Table 3 Results of the Saudi demand (AIDS)

\begin{tabular}{|c|c|c|c|c|c|}
\hline Restrictions & Parameter & Estimate & $\begin{array}{l}\text { Approx Std } \\
\text { Err }\end{array}$ & $\mathrm{t}$ Value & $\begin{array}{c}\text { Approx } \\
\operatorname{Pr}>|t|\end{array}$ \\
\hline (Adding up) & $H_{10}: \alpha_{1}+\alpha_{2}+\alpha_{3}=1$ & 2.06 & 1.53 & 1.35 & 0.182 \\
\hline \multirow{3}{*}{ (Homogeneity) } & $H_{20}: \beta_{11}+\beta_{12}+\beta_{13}=0$ & 13.66 & 34.22 & 0.40 & 0.697 \\
\hline & $H_{30}: \beta_{21}+\beta_{22}+\beta_{23}=0$ & -24.91 & 26.31 & -0.95 & 0.352 \\
\hline & $H_{40}: \beta_{31}+\beta_{32}+\beta_{33}=0$ & 12.17 & 9.18 & 1.33 & 0.189 \\
\hline \multirow{3}{*}{ (Symmetry) } & $H_{50}: \beta_{12}=\beta_{21}$ & 12.91 & 19.14 & 0.67 & 0.509 \\
\hline & $H_{60}: \beta_{13}=\beta_{31}$ & -2.22 & 2.88 & -0.77 & 0.449 \\
\hline & $H_{70}: \beta_{23}=\beta_{32}$ & 39.10 & 30.62 & 1.28 & 0.207 \\
\hline
\end{tabular}

Source: Computed from appendix 1 data. 
Table 4 Price and own-price elasticities and elasticity of expenditure

\begin{tabular}{|c|ccc|c|}
\hline \multirow{2}{*}{ Type of fruit } & \multicolumn{3}{|c|}{ Price and self-price elasticities } & Income elasticities \\
\hline Apples & Apple & Orange & Banana & $0.815^{* * *}$ \\
\hline Oranges & $-0.276^{*}$ & $-0.303^{* * * *}$ & $-0.236^{* *}$ & $1.138^{* * *}$ \\
\hline Bananas & $-0.335^{* * *}$ & $-0.423^{* * *}$ & $-0.381^{* * *}$ & $1.007^{* * *}$ \\
\hline
\end{tabular}

Source: Calculated from the results of regression

\subsubsection{Saudi demand for imported oranges}

From the results mentioned in table 4, it can be concluded that (i) The own-price elasticity of the fruit, $e_{22}$, is significant at 0.01 level, and its estimate, $\hat{e}_{22}=-0.423$, indicates that the Saudi demand for oranges is less elastic for the price of orange imports. Therefore, an increase in the price of imported oranges by $10 \%$ would lead to a $4.23 \%$ decrease in the quantity of imported apples (ii) the cross-price elasticity, $e_{21}$, is significant at a significance level of 0.01 , and its estimate, $\hat{e}_{21}=-0.335$, indicates that the Saudi demand for oranges is less elastic for the price of apple imports. A $10 \%$ increase in the price of apple imports would lead to a $3.35 \%$ decrease in the quantity of imported oranges (iii) The cross-price elasticity, $e_{23}$, is significant at a significance level of 0.01 , and its estimate, $\hat{e}_{23}=-0.381$,indicates that the Saudi demand for oranges is less elastic for the price of banana imports. A $10 \%$ increase in the price of banana imports would lead to a $3.81 \%$ decrease in the quantity of imported oranges and (iv) the demand elasticity of the expenditure demand, $\eta_{2}$, is significant at a significance level of 0.01 . It is estimated that $\hat{\eta}_{2}=1.138$, which indicatesthat the Saudi demand for imported oranges is elastic for the portion allocated out of the total expenditure for all types of imported fruit. A $10 \%$ increase in this expenditure would increase the quantity of imported oranges by $11.38 \%$.

\subsubsection{Saudi demand for imported bananas}

Result mentioned in table 4 suggested that (i) the own-price elasticity, $e_{33}$, is significant at a significance level of 0.1 , and its estimation, $\hat{e}_{33}=-0.266$, shows that the Saudi demand for bananas is less elastic for the price of banana imports. A $10 \%$ increase in the price of banana imports would lead to a $2.66 \%$ decrease in the amount of bananas imported (ii) The cross-price elasticity, $e_{31}$,is significant at a sisgnificance level of 0.05 , and the estimate, $\hat{e}_{31}=-0.298$, indicates that the Saudi demand for bananas is less elastic for the import price of apples. A $10 \%$ increase in the price of apple imports would decrease the required quantity of imported bananas by $4.43 \%$ (iii) The cross-price elasticity, $e_{32}$,is significant at a significance level of 0.01 , and the estimate, $\hat{e}_{32}=-0.443$, indicates that the Saudi demand for bananas is less elastic for the import price of apples. A $10 \%$ increase in the price of apple imports would decrease the required quantity of imported bananas by $4.43 \%$ and (iv) The elasticity of the expenditure demand, $\eta_{3}$, is significant at a significance level of 0.01 , and its estimate is $\hat{\eta}_{3}=1.01$, which indicates that the Saudi demand for bananas is equivalent to the portion devoted to the total expenditure for all three types of imported fruit. Therefore, a $10 \%$ increase inthe portion allocated to expenditure would increase the amount of imported oranges by $10 \%$.

\section{Conclusion}

The study primarily aimed to research and analyzes Saudi Arabia's demand for imported apples, oranges, and bananas by estimating its almost ideal demand system, which uses a system of apparently unrelated equations and non-linear NLS. Based on the results of the study, it can be conclude that the apples, oranges, and bananas are necessary for Saudi consumers, so these fruits need expanding in imports and the diversification of import sources is required to provide these fruit reasonable prices. Further, identification of spatial demands is required to guide importers to places of high consumption within the framework of production and marketing planning.

\section{Acknowledgement}

This research was supported by King Saud University Deanship of Scientific Research, College of food and Agricultural Sciences Research Center. Also the authors thank the Deanship of Scientific Research and RSSU at King Saud University for their technical support.

\section{Conflict of Interest}

Authors would hereby like to declare that there is no conflict of interests that could possibly arise.

\section{References}

Al-Khariji, Vetterstone (1997) Analysis of Demand for Domestic and Imported Chicken in Saudi Arabia Using Bootstrap and Separatism. Journal of the Saudi Society of Agricultural Sciences $9: 161-183$.

Al-Qahtani S (1998) Application of the Rotterdam System and the Linear approximation of the System of the Near Ideal for Foreign Trade of Rice in Saudi Arabia. Journal of the Saudi Society of Agricultural Sciences 10: 163-183. 
Al-Ruwis KBN (2004) Estimation of the Semi-optimal Demand Model (AIDS) on Rice Imports from Major Import Sources in Saudi Arabia. The Literary Journal, Faculty of Agriculture, Cairo University 55: 25-30.

Al-Ruwis KBN, Al-Dirini MM (2008). Estimation of the demand function on the Kingdom's imports of live sheep meat using the quasi-optimal demand model. The Scientific Journal, Qassim University 1:20-35.

Alston JM, Chalfant JA (1993) The silence of the lambdas: A test of the almost ideal and Rotterdam models. American Journal of Agricultural Economics 75: 304-313.

Al-Zum AABA (2001) Determination of the Demand Function of Citrus Imports in Saudi Arabia Using the Semi-optimal Demand Model. Economic Studies, Scientific Series of the Saudi Economic Society 3:33-57.

Buse A (1994) Evaluating the Linearized Almost Ideal Demand System. American Journal of Agricultural Economic 74:781-793.

Central bureau of statistics (2016), Annual report of Central bureau of statistics, Saudi Arabia, 2016.

Deaton A, Muellbauer J (1980) An Almost Ideal Demand System. American Economic Review 70:312-336.
Gravelle H, Rees R (1992) Microeconomics New York; Longman Publishing;

Greene WH (2003) Econometrics Analysis. 5ed. New Jersey; Prentice Hall / Pearson Education International.

Hahn WF (1994) Elasticities in AIDS Models. American Journal of Agricultural Economics 76: 972-977.

Meshaal AAS (2018)Estimation of Meat Demand in Egypt using the Semi-optimal Demand Model. Journal of the Saudi Society for Agricultural Sciences; XVII:19-38.

Nicholson W (1992) Microeconomic Theory: Basic Principles and Extension. 5 ed. Fort Worth, TX; Dryden Press.

Statistical Analysis System (SAS)(2001) SAS/ETS User'sGuide. Version 8.2. Cary, NC; SAS Institute Inv.

Statistical Analysis System (SAS)(2018) Estimating an Almost Ideal Demand System Model. Available on http://support.sas.com/rnd/app/ets/examples/aids/index.htm access on 25th December, 2018.

Yang SR, Koo WW (1994) Japanese Meat Import Demand Estimation with the Sours Differentiated AIDS model. Agricultural and Resource Economics 19:396-408. 